\title{
Los movimientos indígenas y la globalización en los repor- tajes de Manuel Vázquez Montalbán
}

\section{WESELINA GACINSKA}

En el presente trabajo se trata de localizar y analizar las referencias a la problemática indígena y su vinculación con la globalización que Manuel Vázquez Montalbán realiza en su obra, tanto en la poética como, especialmente, en la periodística y ensayística. Aparte de las breves menciones en Pero el viajero que huye (1990) y de varios artículos de prensa, el autor desarrolla su preocupación por los pueblos originarios de América principalmente en dos reportajes largos: en el epílogo de Y Dios entró en La Habana (1998), donde entrevista a Rigoberta Menchú, y en el libroentrevista Marcos: el señor de los espejos (1999). El objetivo es ver la manera en la que el autor y sus entrevistados perciben los movimientos de empoderamiento indígena, su relación con la globalización y el lugar de la antropología en dichas reflexiones, además de realizar una revisión terminológica referente al indigenismo y a los paradigmas de la representación indígena.

El punto de partida para estas reflexiones será el poemario Pero el viajero que huye, donde se encuentran dos menciones a los indígenas, ambas relacionadas con la globalización. El libro gira en torno a la imagen de un mundo confuso y globalizado "donde las identidades nacionales han desaparecido y las relaciones internacionales se han convertido en simples valores de consumo" (García García 366). Este hecho está representado en el poema "Las palabras descansan en la bandeja..." como una confusión lingüística ("los turcos hablan en griego / los griegos hablan en latín con los carabineros"), pero también una unificación, propia de la globalización: "comer es un medio de comunicación de masas / o Mass Communications como dicen los indios" (Vázquez Montalbán, Memoria y deseo 314). La imagen de los indígenas norteamericanos que hablan inglés incide en la pérdida de lenguas originarias y la "americanización" de las etnias.

A su vez, como señala García García, en el poema "En Conemara", los elementos típicamente irlandeses, como las islas Aran o James Joyce "han pasado a ser productos y lugares de consumo, así como la propia actitud de los irlandeses, atrapados e influidos por el imperialismo norteamericano" (366). La representación de esta pérdida de identidad, que 
abarca también a los pueblos indígenas, se muestra en las palabras del poeta de la siguiente manera: "Joyce es una tienda de ultramarinos / la isla de Aran una marca de jerseys / y los irlandeses saludan como apaches / o los apaches saludan como los irlandeses / ambos prisioneros de una película de Ford" (Memoria y deseo 316). La globalización en este caso supone una mezcolanza unificadora que lleva a la pérdida de la identidad cultural en nombre del libre mercado, pero también la dominación del imaginario cultural estadounidense, representado por el western. Llama la atención la elección de la tribu de los apaches, tradicionalmente estereotipada en el cine y la literatura como especialmente salvaje, bandolera, pero también libre. Para ser más precisos, las películas La diligencia (1939) y Fort Apache (1948) de John Ford alientan esta imagen de brutalidad de la etnia sureña. Hay que tener en cuenta que los apaches, que habitan la zona fronteriza de Arizona, Nuevo México y Texas han ganado su fama de indomables por las numerosas rebeliones contra los españoles, los mexicanos y los estadounidenses, para finalmente ser destinados a habitar las reservas, hecho que fomenta la sensación de fracaso. En Marcos: el señor de los espejos, Vázquez Montalbán recurre críticamente a sus primeras referencias acerca de los indígenas norteamericanos, las cuales provenían del imaginario hollywoodense:

La industria cultural estadounidense ha monopolizado el enmascaramiento y el desenmascaramiento del genocidio contra los indios americanos y los españoles, provocadores iniciales del holocausto indígena, perdimos la pista de nuestros indios o creímos que todos habían ido a parar en el mestizaje, error que nos ayudaron a cometer los herederos de la hegemonía española en Hispanoamérica, criollos o ladinos empeñados en no ver a los indígenas. (Mar$\cos 59)$

Los productos culturales cinematográficos, junto con "la filosofía franquista de la Hispanidad", en palabras del barcelonés (59), llegaron a crear una imagen de los indígenas falsificada, uniforme y carente de los matices y de la información básica necesarias para la plena comprensión de las culturas amerindias. Asimismo, Vázquez Montalbán identifica a los indígenas como víctimas, perdedores de la conquista y del sistema neoliberal, denunciando la banalización de las resistencias amerindias, ya que la convicción sobre la futilidad de dichas rebeliones forma parte de la hegemonía occidental (63).

Antes de pasar a los reportajes montalbanianos, es menester establecer un marco de referencia en el cual se insertan los movimientos indígenas de finales del siglo XX. El principal de ellos, merecedor de una 
revisión crítica, es el indigenismo, que se denominará como "histórico" o "político", para no confundirlo con el mismo término utilizado en otro sentido por el autor. El periodo comprendido entre 1920 y 1970 está considerado como "el siglo de oro" del indigenismo, ya que el movimiento intelectual se convierte en el eje de la política social e identitaria en varios países de América Latina. Favre define el indigenismo como "una corriente de opinión favorable a los indios. Se manifiesta en tomas de posición que tienden a proteger a la población indígena, a defenderla de las injusticias de las que es víctima y a hacer valer las cualidades o atributos que se le reconocen" (7). Como movimiento político y social fue desarrollado por los intelectuales vinculados con la academia antropológica, arqueológica y los círculos políticos, constituyendo "una reflexión criolla y mestiza sobre el indio" (Favre 11). Por ende, hoy en día el indigenismo oficial recibe numerosas críticas, tanto por parte de los antropólogos contemporáneos, como por parte de los pueblos originarios. En palabras de Taylor, refiriéndose al caso mexicano, "Indigenismo in Mexico can be characterized as a hegemonic discourse and practice that has facilitated and justified an accelerated internal colonialism toward the second half of the twentieth century in Mexico" (80). A continuación, se realizará un esbozo de las ideas principales elaboradas por los propios indigenistas mexicanos, las cuales son rechazadas y criticadas por Vázquez Montalbán en sus reportajes.

El indigenismo mexicano, inevitablemente, se vio vinculado en su origen con las ideas nacionalistas que surgieron después de la revolución mexicana, que ya estaban latentes en el país desde el siglo XIX. Sin embargo, fue a principios del siglo XX cuando se comenzó a otorgar al indígena un lugar más privilegiado dentro de los discursos políticos. Uno de los ideólogos principales del indigenismo mexicano, Manuel Gamio, como discípulo de Franz Boas (fundador de la escuela de la antropología cultural moderna, que como antropólogo rechazó la teoría evolucionista y difusionista para abogar por el particularismo cultural e histórico), comenzó a percibir la cuestión indígena fuera de sus connotaciones racistas, lo cual potenció el estudio de las culturas precolombinas y, en menor medida, de las etnias contemporáneas. Resulta necesario destacar que los discursos decimonónicos acerca del pasado indígena de México resultaban un tanto contradictorios, a la vez que sumamente racistas. En palabras de David A. Brading,

aunque los principales ideólogos de la insurgencia de 1810, Fray Servando Teresa de Mier y Carlos María de Bustamante, invocaban la grandeza de 
Anáhuac como la mayor gloria de patria criolla, definiendo al pueblo de México como una nación que había luchado tres siglos por liberarse [...], la mayoría de los liberales mexicanos del siglo XIX desdeñaban a los aztecas, a quienes consideraban bárbaros y a los indígenas contemporáneos, a quienes veían como un estorbo para la modernización del país. (212)

Estos prejuicios se mantuvieron vivos hasta los comienzos del siglo $\mathrm{XX}$, cuando el proyecto indigenista irrumpe como un modo de incorporar el pasado y el presente indígena en el imaginario nacional mexicano. El indígena aparece entonces como núcleo de lo auténticamente mexicano. "La más pura fuente de la americanidad, el más vigoroso nexo que liga a los hombres de este continente con el suelo en que viven es el indígena" (Gamio en Villoro 235). La revalorización de las culturas autóctonas se basaba en dos principios: la recuperación de los monumentos arqueológicos que demostraban la grandeza de las civilizaciones precolombinas y el cimiento de la nación, y la incorporación de los grupos contemporáneos a la modernidad nacional. Esto último se realizó a través del ensalzamiento de las artesanías indígenas como muestra más profunda de su singularidad, así como a partir de la aplicación de las medidas educativas que tuvieron como objetivo que las etnias abandonaran el "atraso" en el que estaban sumidas, según los ideólogos indigenistas. Afirma Brading que "el indigenismo, más que una misión, fue el medio para lograr un fin: si su propósito era incorporar a los indígenas, entonces, más que reforzar, habría que destruir la cultura tradicional de las comunidades indígenas" (214).

Uno de los preceptos indigenistas más relevantes, y ya mencionados anteriormente, es la cuestión de la incorporación del indígena a la cultura y a la economía nacional, basándose en una convicción de que los pueblos originarios realmente no forman parte de México y que siguen siendo una especie de "islas" solitarias en el mapa del país. Según Alfonso Caso, "política indigenista significa, en suma, transformar a tres millones de individuos que viven en el territorio nacional, y que son teóricamente considerados mexicanos, en tres millones de mexicanos que realmente contribuyan a su propio progreso" (Caso 50); este objetivo debería cumplirse a través de la educación (ante todo la implantación de la enseñanza del español, aun a costa de las lenguas indígenas) y del acercamiento de la cultura nacional representada por la televisión, la radio, la literatura, etc. Gracias a estas medidas, los indígenas serían capaces de asumir su "mexicanidad" y más fácilmente incorporarse a la economía neoliberal, ya que esto permitiría una mayor migración y un flujo de mano de obra 
de bajo coste. Esta idea la expresan claramente Juan Rulfo y Fernando Benítez en una conversación acerca de los logros del Instituto Nacional Indigenista (INI), del cual ambos formaron parte: "El indio que habla español, que viste de mezclilla, que emigra a las ciudades, que ya no se siente indio ha dejado de serlo. Es un mexicano de tercera o de quinta, pero es un mexicano" (Benítez y Rulfo 127). No deja de ser sorprendente la insistencia de los antropólogos indigenistas en que la incorporación de las etnias a la mexicanidad oficial y estatal se realizaría por medio de tres vías: la educación y el acceso al trabajo, la elaboración de la artesanía para que forme parte del imaginario nacional asumido también por los mestizos y la mejora de las infraestructuras de las comunidades. Los tres puntos, sin embargo, solo serían viables si los pueblos abandonan en su mayoría sus creencias y tradiciones, consideradas como la fuente de su precariedad, ya que, al margen del desarrollo educativo, médico e industrial resultaba necesario lograr el progreso propuesto por los indigenistas también en el campo de la cultura espiritual. La exigencia del abandono de las "supersticiones" y de las antiguas creencias que supuestamente impiden el desarrollo de las comunidades es una cuestión, a día de hoy, cargada de negatividad, y genera un gran rechazo en el seno de la comunidad antropológica, ya que dichas prácticas quedan tildadas como colonizadoras, eurocéntricas y paternalistas. Es preciso llamar la atención sobre este aspecto de los discursos y las prácticas indigenistas que más ha afectado a las poblaciones hasta el día de hoy (la erradicación de las prácticas culturales, sobre todo), a pesar del aparente objetivo indigenista de la protección de las mismas.

Respecto a la parte espiritual de los indígenas, a la que también se refieren y reivindican Rigoberta Menchú y el subcomandante Marcos, para los antropólogos de medio siglo el sincretismo religioso o las supervivencias de algunas creencias de origen antiguo siguen estando consideradas como muestras de su infantilidad mental y del pensamiento prelógico (a la manera de hablar de los evolucionistas decimonónicos). Refiriéndose a la cuestión del sincretismo religioso en México, Manuel Gamio, el autor de Forjando patria, dice al respecto:

La religión cristiana no logró ser asimilada plenamente. Permaneció en un estado grosero, mezcla burda de catolicismo y paganismo. Por ello en lugar de lograr un adelanto espiritual, sólo causó retroceso. Eliminó todo lo que de grande y moralizador tenía la religión autóctona para dejar de ésta sólo groseros ritos y supersticiones infantiles. Privados de su impulso religioso original, de la mitología y los dioses que los inspiraban, los indios poco o nada 
recibieron a cambio; pues que no perdieron o no supieron asimilarse los nuevos y elevados valores religiosos que el español les aportaba. (Gamio en Villoro 231)

Los aspectos culturales y religiosos, así como la creación de la imagen del indio, pertenecen al campo que más críticas y polémicas puede suscitar. Los órganos de difusión indigenista en el suelo mexicano, las revistas México Indígena y Acción Indigenista ${ }^{1}$ creadas y publicadas por el Instituto Nacional Indigenista (INI), comparten un mismo mensaje acerca del estudio de las culturas originarias, como se muestra a continuación:

Comunidades que aún sobreviven en regiones inhóspitas y marginadas del progreso; pero cuyas fronteras y peculiaridades propias encierran características y costumbres de gran interés y son fuente igual que verifican como dichas comunidades, sin abandonar su identidad tradicional, van incorporándose lenta e ineludiblemente a los destinos de la nación a la que pertenecen. (“Presentación 13)

Los reclamos por mantener la identidad cultural de los indígenas se ven contrariados en la práctica, ante todo lingüística, en la que uno de los objetivos fue la "españolización" de las escuelas, con la exclusión de la instrucción en las lenguas nativas. A su vez, como se ha mencionado anteriormente, la expresión cultural de los pueblos se limitaría a la elaboración de las artesanías, como muestra de lo más representativo de ellos, sin tener en cuenta la cultura inmaterial, el conocimiento médico, la literatura oral, el sincretismo religioso y las formas de organización y autogestión que también forman parte del legado cultural. La tensión constante reside entre los reclamos del valor de las culturas indígenas, elevadas al mismo nivel que otras manifestaciones culturales mexicanas,

${ }^{1}$ La revista México Indígena fue creada en 1948 y su publicación cesó en 2003. A su vez, la publicación mensual Acción Indigenista. Boletín del Instituto Nacional Indigenista (1953-1976) muestra numerosas similitudes en cuanto a los contenidos, siendo más sencilla en la forma. El objetivo de ambas revistas fue difundir a través del INI los ensayos y estudios de los antropólogos mexicanos (tanto teóricos como los trabajos de campo) referentes a las culturas amerindias mexicanas. En la mayoría de los casos, el mensaje indigenista del INI fue mostrado por el equipo editorial de manera anónima, como es el caso de la presentación del número citado en este trabajo. 
y la problemática de percibir al indígena como una figura casi literaria, ajena al mundo real, estereotipada y limitada por su exotismo y los "secretos" que esconde su alma.

En las primeras páginas de Marcos: el señor de los espejos, Vázquez Montalbán recurre a las palabras de Roger Bartra acerca del papel del salvaje en la imaginación colectiva occidental. Según el pensador mexicano, resuena de modo crítico la imagen del "buen salvaje" marcada por el secretismo, el misterio y la relación cercana con la naturaleza. Vázquez Montalbán recoge la idea de Bartra según la cual el indígena es la clave de Occidente, un espejo en el que la cultura occidental pueda encontrar su sentido, reivindicando asimismo la presencia y el papel de las etnias en los ecosistemas culturales (Marcos 18). El autor no duda en mostrarse crítico con las políticas indigenistas, ante todo refiriéndose al imaginario creado en la primera mitad del siglo XX alrededor de la figura del indígena. Señala que su presencia en la cultura y en la historia se limita a ser un telón de fondo y a mostrar una visión altamente limitada de la presencia amerindia en México. Haciendo suyas las palabras de Bonfil Batalla, dice que "la presencia de lo indio en los muros, museos, esculturas y zonas arqueológicas abiertas al público traduce la presencia de un mundo muerto" (Marcos 65). Por tanto, los reportajes-entrevistas comentados en este trabajo cumplen un papel importante que consiste en otorgar voz y protagonismo a estos sujetos subalternos, molestos e incómodos para las élites políticas de finales del siglo XX, que seguían aplicando las premisas de las políticas indigenistas tempranas.

En el epílogo de $Y$ Dios entró en La Habana, al referirse a Chiapas y al libro de Marta Harnecker La izquierda en el umbral del siglo XXI, Vázquez Montalbán habla de una "izquierda emergente, mestiza de indigenismo cultural y social, más próxima a los zapatistas de Chiapas o a los combativos luchadores sociales brasileños que a los Politburós" $(Y$ Dios 682-683). El autor, al señalar estos nuevos movimientos de izquierda en América Latina, muestra una visión esperanzadora y busca en ellos el componente renovador de la política y de las relaciones sociales. Al describir el perfil de la izquierda y de las nuevas tendencias políticas, no duda en aplicar los términos referentes al mestizaje y al indigenismo, ambos con un peso semántico notable en los países de Hispanoamérica. Vázquez Montalbán define el "nuevo indigenismo" en función de cómo él entiende los movimientos de raíz indígena: "El indigenismo tal como se está recibiendo mediáticamente aparece como un movimiento de carácter ético, una reivindicación moral, pero con aspiración de tener pre- 
sencia política. Samuel Ruiz, el obispo de Chiapas, dijo que verá al indígena como el sujeto de una nueva evangelización" ( $Y$ Dios 695).

El cambio de paradigma montalbaniano en torno al término "indigenismo" ocurre cuando Menchú y el autor conversan acerca de los movimientos indígenas a nivel mundial. Se habla de "movimientos indigenistas", "contestación indigenista", "indigenismo creado por la esclavitud", etc. ( $Y$ Dios 700-701). El autor acuña un término curioso hablando del "indigenismo precolombino", para referirse a los pueblos amerindios. Uno de los aspectos destacables de estas reflexiones es que la lucha indígena debe producirse y tener en cuenta a otras minorías étnicas desfavorecidas, ante todo en el aspecto económico. También, a la hora de trazar el retrato del subcomandante Marcos, dice:

El subcomandante es algo teatral, obligado por la naturaleza de su escenario y como réplica a las farsas del supermercado de la modernización uniformadora o de los restos del naufragio semántico del marxismo leninismo. Representa insurgencias esenciales: el indigenismo como sujeto internacional, el mestizaje como lo deseable más que como lo inevitable. (Y Dios 713)

En definitiva, el hecho de identificar el "indigenismo como sujeto internacional", no solamente otorga un matiz positivo a la iniciativa social, sino que también incide en el mestizaje del proyecto, por un lado, parcialmente basado en las creencias y estructuras indígenas y, por otro, como algo novedoso en términos de crear una nueva calidad cultural. En un libro de entrevistas con Georges Tyras, Vázquez Montalbán define el zapatismo como una nueva propuesta de la izquierda moderna, "representante de una vanguardia de la sociedad civil crítica" (Tyras 218). Según las propuestas e intenciones del mismo EZLN, la novedad de la rebelión, que no revolución, zapatista reside ante todo en la cuestión del poder y de la democratización de sus estructuras, así como en la involucración de amplios sectores de la sociedad en la reivindicación de los derechos de las comunidades indígenas, sin olvidar el papel activo de las propias etnias, a su manera. Hay que tener en cuenta la gran diferencia entre las propuestas políticas de las izquierdas emergentes latinoamericanas y las europeas, caracterizadas estas últimas por su estancamiento. Para Vázquez Montalbán, partiendo de la injusticia que supone la voz "silenciada" de los indígenas a lo largo de la historia, los zapatistas representan no solamente una renovación, sino también una gran y profunda propuesta intelectual y cultural, como señala en Marcos: 
En silencio ven y se ven estos indígenas. En silencio sienten para dónde soplan los aires de los mundos de abajo. En silencio saben estos indígenas. En silencio terminan esta nueva y absurda arca de Noé, sabiendo que el aire sopla para la democracia, la libertad y la justicia, plantan bien alta la doble vela de la esperanza, motor y luz para este navío, el barco de los de siempre, la nave de la vida. (Marcos 45)

El aspecto profundamente renovador del movimiento es subrayado también por Carlos Taibo (155-156), el cual señala que los puntos principales de la apuesta zapatista, no solo a nivel nacional, residen en la horizontalidad, la autogestión y la democracia directa, pero también en la oposición a la dominación por parte del estado de los servicios básicos, por no mencionar su oposición al libre mercado. También, como se ha mencionado al principio, estos movimientos adquieren unas nuevas denominaciones terminológicas en el campo de las ciencias sociales. Las corrientes de base indígena, o mayoritariamente indígenas, llegan a adoptar el nombre de "indianismo" para diferenciarse del indigenismo histórico, e incluso anarcoindigenismo (Taibo 164) con el propósito de reforzar la idea de la rebelión de dichos grupos ante el estado. Por supuesto, en este caso el término "indianismo" no debe confundirse con el movimiento literario del s. XIX, sino que constituye una propuesta política sui generis.

Vázquez Montalbán también insiste en el carácter innovador de la rebelión chiapaneca en Y Dios entró en La Habana: "Esta revolución es el ruido que se ha colado en el canal de comunicación del pensamiento único, es el enemigo a batir y se estrecha el cerco en torno a su irresistible originalidad" (686). El papel de los zapatistas y del peso mediático del Subcomandante Marcos tiene como fin no solamente la renovación de la izquierda y la resignificación de la lucha, de la justicia, sino también "recuperar el papel del humanismo para ordenar el caos capitalista" (687). El zapatismo, según Vázquez Montalbán, supone la vuelta al origen, lejos de las etiquetas "pos-" aplicadas a las diferentes esferas del panorama político y social. ${ }^{2}$ Una de las medidas que adopta el zapatismo, y que Vázquez Montalbán transmite a sus lectores, es la búsqueda (y también la creación) del mito original y de los referentes indígenas frente a la impostación de la cultura de masas.

2 “Atención a Chiapas, porque allí se está jugando el sentido ético de este fin de milenio, como un referente simbólico de la esperanza como virtud laica" ( $Y$ Dios 687). 
El subcomandante Marcos, en la primera carta que dirige a Vázquez Montalbán en diciembre de 1997, incluida en Y Dios, a la hora de hablar de la resistencia indígena en la selva Lacandona recurre a la figura de un rebelde maya de la época colonial, Jacinto Canek, y cita sus supuestas palabras sobre la explotación de las tierras de los indígenas por los colonizadores blancos:

Los blancos hicieron que estas tierras fueran extranjeras para el indio, hicieron que el indio comprara con su sangre el viento que respira. Por esto va el indio, por los caminos que no tienen fin, seguro que la meta, la única meta posible, la que le libra y le permite encontrar la huella perdida, está donde está la muerte. (Y Dios 708)

Resulta notable la elección de Canek como referente, ya que dicho líder indígena, cuyo nombre real era Jacinto Uc de los Santos, protagonizó una rebelión en el poblado Cisteil que comenzó el 19 de noviembre de 1761. El apodo por el que se dio a conocer Canek tiene un significado milenarista, pues se presentó ante los habitantes de Cisteil como rey y aseguró tener poderes mágicos y chamánicos, y su llegada, como encarnación de Moctezuma, había sido anunciada como profecía. Según Robert W. Patch, "su comportamiento como chamán convenció a los indígenas del pueblo que él era el rey. Y cuando los líderes religiosos de Cisteil declararon que Uc era el monarca legítimo, fue coronado Jacinto Uc de los Santos, Can Ek, Rey Montezuma". La figura de Canek, recuperada en el discurso por Marcos, pretende representar no solamente la inserción de la rebelión zapatista en la larga tradición de los levantamientos indígenas contra el poder colonial, sino también subrayar la importancia que tuvo en la rebelión de Cisteil el componente mítico, en el que tanto insiste el EZLN. Para Patch, el levantamiento encabezado por el rey Canek posee un trasfondo cultural, antes que económico, basado en la idea de un mundo cíclico, donde la colonia es solamente una fase que debe transcurrir e invertirse antes de que los indígenas recuperen su autonomía y el poder sobre sus tierras. ${ }^{3}$ Además, la elección del

${ }^{3}$ Patch establece que, "a pesar de los siglos de colonialismo y cristiandad, los mayas continuaban creyendo que el tiempo no se movía a lo largo de un continuит sino en ciclos y que el régimen colonial era sólo una fase en esta historia cíclica. De hecho, los españoles eran vistos simplemente como otro grupo conquistador que eventualmente sería depuesto e integrado a la sociedad indígena" ("La rebelión"). Y continúa acerca de la recuperación del poder por parte de la población autóctona: "En realidad, los mayas que participaron en el movimiento 
nombre Canek, el último rey de los itzaes independientes, y su identificación con Moctezuma demuestran una acumulación de símbolos de poder, independencia, poderes sobrenaturales y el deseo de figurar como el heredero de los héroes culturales indígenas. Dicho esto, es menester regresar a la cita que ofrece Marcos. Más allá del significado cultural y político que ya se ha expuesto acerca de Canek, las palabras que cita el subcomandante no pertenecen al líder maya, sino que provienen de la obra de teatro titulada Canek, escrita por Emilio Abreu Gómez y publicada en 1940. El autor y su producción literaria tuvieron un gran impacto a nivel regional en su época, ya que precisamente trataban de recuperar la memoria cultural de los pueblos mayas de Yucatán.

Aparte de su aprecio por los zapatistas, Vázquez Montalbán no disimula su admiración por Rigoberta Menchú, a quien llega a identificar como "institución ambulante que cumple el papel de ser el sistema de señales no rechazable de la existencia del desorden económico, político, social y cultural" y "poder global simbólico" ( $Y$ Dios 688). Refiriéndose a las palabras de Gianni Minà, quien la denomina "una metáfora de indigenismo", el autor alude a la historia de la vida de Menchú, especialmente las tragedias familiares y la experiencia de la violencia ejercida contra la población indígena. De esta manera, Vázquez Montalbán, junto con los colaboradores y seguidores de la guatemalteca, convierte a Menchú en una síntesis y un ejemplo de muchas familias indígenas de Guatemala. En el libro de Georges Tyras, el barcelonés reconoce que el encuentro con la lideresa guatemalteca pretendía ser un aprendizaje y una oportunidad de escuchar las voces contestatarias, así como conocer de primera mano las experiencias de las víctimas del poder, los perdedores que llevaban siendo dominados desde hace quinientos años, debido a las secuelas de la conquista:

Indagar sobre las relaciones de dominación en aquella época me impuso ir a los lugares donde los perdedores lo eran doblemente: no eran sólo perdedores del sistema directo, sino que acumulaban perdedores desde hacía quinientos años, los que habían perdido la conquista, los que habían sufrido la colonización y que además estaban condicionados a ser elementos completamente marginales en el proceso de producción y de comercio. (Tyras 205)

no estaban resistiéndose a la autoridad; la estaban reclamando para sí mismos. Por esta razón no hicieron ningún intento de negociar con el gobierno español para reparar los agravios del colonialismo". 
En la entrevista con Vázquez Montalbán, Menchú admite que en muchas ocasiones los portavoces de los pueblos, entre los que ella misma se encuentra, tienden a la idealización y a la exageración de los valores culturales indígenas: "muchas veces llegamos a la idealización de lo nuestro y a presentar lo indígena como algo intacto y con mucho radicalismo. Hemos sido contestatarios y por eso contestamos a las ofensas contra nuestros pueblos" (Y Dios 690). Este es uno de los aspectos que más duramente ha sido criticado por los lectores de Menchú, y también por los antropólogos, en lo que concierne a las cuestiones identitarias. Sin embargo, el barcelonés no pone en cuestión la exposición de los valores amerindios realizada por Menchú o el subcomandante. Dentro de esta idealización, se integran diferentes aspectos que la activista comenta en la entrevista:

Hay que establecer nuevos lazos entre las dos culturas, sin volver a darle la hegemonía al extranjero que viene a investigarnos con criterios meramente antropológicos. Hay que dar función a los sabios indígenas: a los educadores locales, a las comadronas, a las personas que han ganado un liderazgo de muchos años entre los suyos. Se habla de diálogos, de solución política a conflictos, pero desde una esfera distinta, y los sabios indígenas tienen su método de solución política de los conflictos basado en las relaciones interfamiliares, en el conocimiento territorial. (Y Dios 691)

Como se ve, la insistencia recae en la esperanza de tener más líderes indígenas de procedencia étnica que puedan ocupar las alcaldías o en la elaboración y presentación de una opción política fuerte y reconocible a nivel nacional. En palabras de Menchú:

Nuestra gente no ha tenido la oportunidad de crear estructuras de poder, participación activa en la economía, en la política, aunque sí se representan las reglas constitucionales; desde la política nuestra gente podía actuar, porque ya tenemos experiencia, pero no en la administración de empresas ni en el manejo de los recursos potenciales. Los hermanos ladinos usaron durante siglos su hegemonía en estos campos. (Y Dios 692)

Uno de los aspectos de más peso, y que a su vez supone una reivindicación contemporánea derivada de la oposición a las políticas coloniales y el indigenismo histórico, es la cuestión lingüística y la demanda de la inclusión de las lenguas indígenas en las agendas políticas y educativas. El bilingüismo en Guatemala se plantea como una vía para todos los habitantes del país y como una forma de emancipación y empoderamien- 
to de los indígenas; más que hacer que los indígenas aprendan español (según las políticas actuales, ya son bilingües), lo que se pretende es que la población ladina se acerque a las culturas indígenas también a través del idioma. ${ }^{4}$ Dicho planteamiento resulta innovador y, a su vez, posee una gran importancia, especialmente teniendo en cuenta la marginalización de las etnias debido a las barreras lingüísticas y el racismo que de allí deriva. Una educación en materia de las diferentes culturas aborígenes guatemaltecas se propone como un intercambio cultural dentro de Guatemala, una especie de "normalización" del indígena y una vía en el camino a su desexotización.

En lo que a la globalización se refiere, Menchú la considera como el principal impedimento para el bienestar de los pueblos amerindios, ya que, según su forma actual, las comunidades quedan excluidas del libre mercado. Lo que propone entonces es la incorporación de los indígenas en el comercio mundial, idealizando, posiblemente, las nuevas formas que puede adquirir el sistema neoliberal: "No satanicemos tampoco la globalización. Encontremos lo bueno que tiene. El libre comercio y la libre comunicación son positivos si realmente es libre comercio y no un control tramposo en beneficio de las multinacionales" ( $Y$ Dios 698). Hay que destacar que la líder en ningún momento menciona la forma en que los indígenas deberían participar en el comercio mundial, ya que hasta la fecha las personas provenientes de las etnias, como migrantes o artesanos, únicamente tenían la oportunidad de buscar trabajo en los sectores más precarios (de hecho, tal reivindicación ya se realizaba con el indigenismo histórico).

El último punto que se abarcará en este trabajo será la cuestión de la antropología y cómo Marcos, Menchú y el autor catalán perciben a los profesionales de esta disciplina. Vázquez Montalbán expresa de la siguiente manera la posición de los indígenas dentro del marco del zapatismo y dentro del marco de la sociedad mexicana: "Allí está la revolución zapatista con un código pegado a la lógica de los indígenas, a su sustrato cultural y a su querer superar la condición de carne de cacique o

${ }^{4}$ Como Menchú señala en la entrevista con el autor: "Guatemala será bilingüe. No para los indígenas, sino para todo el mundo. Nuestros padres tuvieron que usar el español por obligación, porque todos los mensajes culturales e informativos se dan en español: radio, televisión, todo; por tanto, somos bilingües de nacimiento, pero también somos multilingües en cuanto a los idiomas interculturales del país. La educación actual está planteada para no-indígenas" (Y Dios 693). 
de carne de antropólogo" ( $Y$ Dios 686). De nuevo, se insiste en la importancia de la autogestión y la autodeterminación de las etnias, en su difícil posición política y en la red de dependencias en las que se veían (y siguen viendo) involucradas, así como en el peso que ejerció el indigenismo histórico y la percepción del antropólogo como un invasor y un sujeto irrespetuoso que objetualiza a las etnias. Menchú, por su parte, recrimina la labor antropológica a raíz de la aparición de sus memorias y del surgimiento de las voces indígenas en el debate mediático: "Yo recuerdo que fue la primera vez que oí a tantos intelectuales, profesionales, críticos con la línea antropológica occidentalista hacia los pueblos indígenas hegemónica durante décadas. Allí donde habla un indígena aparece un antropólogo para sancionar lo que dijo el indígena" (Y Dios 701). Asimismo, la lideresa guatemalteca muestra su punto de vista acerca de algunos aspectos de la cultura autóctona a la que pertenece, como, por ejemplo, en lo referente al sincretismo religioso y a sus creencias personales, se ha hablado ante todo de la posibilidad y la naturalidad de asumir la religión antigua a la par que la católica o la evangélica. Se naturaliza, así pues, que se recurra a las praxis indígenas (prácticas naturales de parto, la medicina tradicional o la participación en los rituales) y, al mismo tiempo, se forme parte de la iglesia, $\mathrm{y}$, además, se da a entender que este sincretismo está extendido en una gran parte de la población ( $Y$ Dios 702). A la pregunta de Vázquez Montalbán sobre si son peligrosos los antropólogos, Menchú responde que "frecuentemente han sido irrespetuosos" ( $Y$ Dios 701).

En este punto es necesario referirse a la polémica surgida alrededor de la autobiografía realizada por Menchú junto con Elisabeth Burgos-Debray titulada Me llamo Rigoberta Menchú y así me nació la conciencia (1983). A raíz de la publicación de David Stoll en 1999, Rigoberta Menchú and the Story of All Poor Guatemalans, se ha generado un conocido debate acerca de la veracidad del testimonio de la Premio Nobel, en el que uno de los ejes principales fue la dicotomía entre la memoria y la historia. Vázquez Montalbán, en uno de sus artículos de prensa, no dudó en calificar la lluvia de críticas que recayó sobre Menchú como una "campaña de deslegitimación del indigenismo político" o como una "ofensiva contra la Menchú" ("Rigoberta"). El autor mantuvo su postura de defensa de la guatemalteca, insistiendo en la dramaticidad de sus experiencias durante la guerra y la guerrilla, así como en el acoso que sufrió por parte de los antropólogos, a quienes Vázquez Montalbán califica como "frente antropológico-pijoliberal antiindigenista" ("Rigoberta"). A su vez, hay que señalar que las posturas que el autor rechaza y critica duramente destacan por su 
afán de buscar la mesura y por demostrar la complejidad étnica y cultural de las zonas en cuestión. Pedro Pitarch, antropólogo especializado en las culturas amerindias chiapanecas y guatemaltecas, se acerca al libro de Stoll de una forma muy conciliadora:

Los testimonios poseen un carácter ambivalente. Por una parte reflejan la vida personal de la persona que cuenta su vida, pero a la vez aspiran a presentar la voz y experiencia de grupos sociales enteros: en el caso de Menchú, los indígenas guatemaltecos. En realidad, la verdad o falsedad del relato es algo que tiende a considerarse secundario, cuando no completamente irrelevante. Lo que interesa (por lo general a los antropólogos, quienes más cultivan este género) es la capacidad del narrador de mostrar su forma de entender el mundo y, por extensión, la vida del grupo social al que pertenece. El testimonio puede tener mucho de ficción, pero no por ello es falso. ("El testimonio")

Pitarch insiste en la necesidad de llevar a cabo unos estudios minuciosos de contrastación de los testimonios y la verificación de hechos, así como la matización de las relaciones dentro de las propias comunidades y de aquellas con otros grupos indígenas, y así tratar de comprender el peso y la agenda política de los testimonios como el de Menchú. Asimismo, Pitarch advierte el éxito del libro de la guatemalteca tanto en Europa como en Estados Unidos, y que, más allá de la visibilidad de los indígenas y las muestras de solidaridad que ocasionó, supuso también el estancamiento de la imagen de los amerindios como seres auténticos, puros y telúricos. Según Pitarch,

en efecto, el testimonio de Menchú tiende a presentar el mundo indígena idílico, fundado en la vida comunitaria armoniosa y el rechazo de la tecnología moderna. Y este sesgo quizá explica también los silencios sobre algunos aspectos de su vida. Por ejemplo, la insistencia en presentarse como una persona iletrada y monolingüe. Rasgos así ayudaban a proporcionar la imagen de indígena incontaminado que se requería. En este sentido, el relato de Rigoberta es una víctima de prejuicios, del racismo al revés: si los indígenas no se presentan ante los movimientos de la solidaridad internacionales de acuerdo con las imágenes formularias que se les atribuye, la posibilidad de atraer su atención y ayuda se complica. ("El testimonio")

El antropólogo insiste en la necesidad de ver la figura de Menchú como una representante de su pueblo y como un símbolo de una causa, más allá de sus peculiaridades que no encajarían en una vida modélica, 
lo cual no resta nada de dramatismo a sus vivencias y el respeto que todo ello suscita. Tampoco es el único en resaltar los aspectos culturales para argumentar sobre el testimonio de Menchú: Octavi Martí (1999) en una de sus columnas insiste en que las inexactitudes no deberían ser indignantes para nadie al tratarse de un caso de memoria colectiva común y de una tradición oral, y que las historias contadas por la guatemalteca poseen un valor de representación de un colectivo mucho más amplio.

En Marcos: el señor de los espejos, el autor entabla una conversación con el subcomandante Marcos acerca de la antropología, durante la cual alude a las palabras de Menchú sobre la distorsión de la imagen de los indígenas creada por los antropólogos, así como a un artículo que apareció en El País acerca de Chiapas y los zapatistas:

Es curioso que un antropólogo español, razonara en El País que vosotros como intermediarios habéis falsificado "la verdadera" imagen del indígena. Hasta ahora no se habían quejado del PRI como intermediario. Yo creo que hay dos clases de antropólogos. Los que han creado una imagen falsificada, como si estuvieran coleccionando mariposas o insectos, pero también ha habido un sector que ha llamado la atención sobre el respeto a esa diferencia. (Marcos 162-163)

Se puede deducir que el antropólogo español al que se refiere Vázquez Montalbán es Pedro Pitarch, y que las palabras del texto que cita provengan de su texto titulado "Chiapas", publicado, efectivamente, en El País el 12 de enero de 1998. En este artículo el antropólogo llama la atención sobre la complejidad de los tejidos sociales y culturales de los Altos de Chiapas y la heterogeneidad de las organizaciones políticas y religiosas que allí actúan. ${ }^{5}$ Contrario a la opinión del barcelonés, Pitarch insiste en el gran pluralismo de las comunidades y en la fuerza de la resistencia frente a los factores externos que han permitido el mantenimiento de su identidad. A su vez, expresa una crítica hacia el zapatismo y sus formas de actuación en el seno de las comunidades:

\footnotetext{
5 "Más que en ninguna parte, entre los indígenas de Chiapas las etiquetas políticas resultan enormemente engañosas. Hablar de indígenas protestantes resulta tan artificial como hablar de indígenas revolucionarios: un día se identifican como tales, al día siguiente no. De hecho, en la comunidad tzeltal donde he trabajado, uno de los rasgos más característicos es el continuo cambio de miembros de unas organizaciones a otras, un incesante nomadismo que desespera a los dirigentes políticos, sacerdotes y pastores por igual" (Pitarch "Chiapas").
} 
Otras medidas no ayudaron: restar poder a los ancianos en favor de los jóvenes militarizados, expulsar a los chamanes bajo la acusación de ser "brujos" o prohibir rigurosamente el consumo de aguardiente son todas las medidas que, por anecdóticas que puedan parecer, amenazan directamente el corazón de la tradición indígena. Por lo demás, este tipo de actitud tiende a situar a los zapatistas en el mismo campo "activista" que los protestantes y los neocatólicos, y les enfrenta a los indígenas de cultura más tradicional, organizados de manera menos militante y también menos capaces de hacerse escuchar. ("Chiapas")

Hay que subrayar que con su postura lo que pretende Pitarch es, ante todo, dar prioridad a las voces indígenas y no a los intermediarios, y advierte además sobre el peligro de alimentar las falsas imágenes estereotipadas de las comunidades:

los indígenas aparecen como la encarnación de valores occidentales: son así convertidos alternativamente en revolucionarios modelo, en comunidades cristianas de base en su estado más prístino, en depositarios de la esencia de México, en guardianes de vastos saberes místicos, en ejemplo del respeto por la naturaleza o cualquier otro. Pero esto, mal que nos pese, no es así. ("Chiapas")

Para concluir, en este trabajo se ha tratado de demostrar que el acercamiento de Vázquez Montalbán a las figuras indígenas y la temática indígena ha cambiado y se ha ampliado desde las breves referencias en Pero el viajero que huye hasta los reportajes en los que se tratan estas cuestiones. Si bien en el caso de los poemas la visión montalbaniana estaba más vinculada con la imagen cinematográfica procedente de los westerns altamente occidentalizada, en los reportajes referentes a las rebeliones indígenas este enfoque cambia. En los poemas mencionados el "indio" es el objeto, una mera imagen del mundo del entretenimiento presentada críticamente como imagen falsificada, pero más adelante Vázquez Montalbán reivindica la voz de los indígenas, con la pretensión de ser un canal de difusión en el mundo occidental de las ideas que él denomina como indigenistas: ideas de autonomía, de rebelión contra la globalización y de la defensa de los valores culturales amerindios. Su proceder se dirige contra las numerosas críticas que ha recibido el zapatismo en los medios de comunicación convencionales, reacios a la rebelión y contrarias a la validez de las reivindicaciones indígenas. Antes de llegar al encuentro con el subcomandante Marcos, Vázquez Montalbán confesó lo siguiente: 
Mientras tanto ya me he preguntado varias veces qué hago aquí y qué sé de cuanto me rodea, hasta el punto de que se corresponda o no a mi imaginario del mundo indígena, alimentado por el recorrido por la geografía del exterminio de la América blanqueada, el Cono Sur o de un reciente, intenso viaje a Guatemala, de sur a norte, a través de las venas de América Latina. (Mar$\cos 57)$

Vázquez Montalbán, a lo largo de su recorrido por las políticas y las culturas chiapaneca y maya guatemalteca, resalta la noción de la supervivencia de las comunidades a pesar de las políticas nocivas desde los tiempos coloniales a los neoliberales. La necesidad de recuperar el "México profundo" (haciendo suyo el término y título del libro homónimo de Bonfil Batalla del año 1987), de revisar el concepto de mestizaje y de replantearse el papel de los amerindios en las sociedades hispanoamericanas contemporáneas, es ineludible no solamente por cuestiones cuantitativas, sino por mera justicia histórica y económica con los oprimidos (Marcos 206). Estas cuestiones, como se ha señalado al principio del trabajo, están inevitablemente relacionadas con la visión esperanzadora y la búsqueda que ha realizado Vázquez Montalbán de propuestas de una nueva "izquierda emergente", $\tan$ distintas de los planteamientos de las "viejas izquierdas" europeas, por su audacia y reclamo de una profunda transformación política y cultural. El compromiso político e ideológico del barcelonés con ambos líderes, a los que se acerca con motivo de aprender, comprender y empatizar, deriva en unos reportajes que, sobre todo en el caso del Subcomandante Marcos, tienen una repercusión importante en los medios de comunicación españoles y mexicanos, y a su vez constituyeron algunos de los primeros acercamientos a estas realidades políticas en los albores del nuevo milenio. A pesar de los modelos diferentes de la lucha zapatista y los reclamos de Rigoberta Menchú, Vázquez Montalbán logra trazar una línea que vincula y reivindica ambas propuestas, provengan bien del portavoz enmascarado de los indígenas de la Selva Lacandona, bien de una activista política guatemalteca identificada profundamente con sus raíces indígenas. Sin embargo, la relación que establece Vázquez Montalbán con Menchú y Marcos es notablemente distinta. En el caso de la guatemalteca, el autor, tal como señala en la entrevista citada con Tyras, se acerca a Menchú con el fin de comprender y relatar de primera mano las demandas y los discursos de la Premio Nobel de la Paz como representante de las comunidades indígenas de Guatemala. Por su parte, con Marcos profundiza en cuestiones políticas y económicas a un nivel diferente: Marcos no deja de ser un 
portavoz, un vínculo entre las demandas de las comunidades lacandonas y el periodista, con el que participa del imaginario cultural occidental.

Sin embargo, como se ha tratado de demostrar a partir de la revisión terminológica que se ha realizado, la carga idiosincrásica establecida con el indigenismo histórico continúa vigente y sigue afectando a la percepción globalizada de las comunidades amerindias. La actitud colonial y paternalista del indigenismo cultural que ha establecido la representación del indígena como un ser silenciado, místico, misterioso e inaccesible, pero al fin y al cabo merecedor de la atención de los antropólogos y de los demás ciudadanos, no dista excesivamente del concepto del "buen salvaje". A pesar de la enorme validez y necesidad de las reivindicaciones políticas y sociales que surgen desde el zapatismo o las propuestas políticas de Rigoberta Menchú, la vía que han tomado dichos actores, y la manera en la que Vázquez Montalbán trasmite en sus páginas la información y la reflexión sobre las culturas indígenas, se ve afectada por el mismo pensamiento indigenista tradicional. Recordando las palabras de Pitarch, la simplificación y la idealización de las comunidades y de las propias culturas amerindias, exceptuando los aspectos más conflictivos o insistiendo en las imágenes telúricas, en la representación de la vida de las comunidades como una armonía absoluta con la naturaleza (y un largo etcétera), no deja de constituir otro tópico. Gracias a los movimientos indígenas los pueblos han logrado tener voz (que anteriormente les había sido negada), presencia e interés en los medios de comunicación a gran escala en su búsqueda de poder y derecho a la autodeterminación, unidos al conocimiento cultural de las comunidades. Sin embargo, este logro ha sido conseguido gracias a la repetición de los patrones tradicionales. Asimismo, tal como se anunciaba al principio de este trabajo, la resignificación del término "indigenismo" en Vázquez Montalbán es parcial. El autor, utilizando esta denominación para referirse a la lucha indígena, lo que trata es de subsanar las políticas nocivas hacia las comunidades, y realiza una labor importante de reivindicación e inversión de roles. Sin embargo, las imágenes ofrecidas inevitablemente están vinculadas con una tradición occidental, y los imaginarios culturales indígenas son adaptados para el lector europeo.

\section{Bibliografía}

Abreu Gómez, E. Canek. Mérida: Gobierno del Estado de Yucatán, 2008. Impreso. 
Benítez, Fernando y Juan Rulfo. "Juan Rulfo y Fernando Benítez hablan sobre los indios". México Indígena. INI 30 años después. Revisión crítica, núm. extraordinario diciembre (1978): 125-128. Impreso.

Brading, David A. Mito y profecía en la historia de México. México DF: Fondo de Cultura Económica, 2004. Impreso.

Caso, Alfonso. Indigenismo. México DF: Instituto Nacional Indigenista, 1958. Impreso.

Favre, Henri. El indigenismo. México DF: Fondo de Cultura Económica, 1998. Impreso.

García García, Sergio. La poesía de Manuel Vázquez Montalbán: 19632003. Madrid: Universidad Autónoma de Madrid, 2019. Tesis doctoral.

Martí, Octavi. "Las mentiras piadosas de Rigoberta Menchú". El País, 3 enero 1999. Web.

Patch, Robert W. "La rebelión de Jacinto Canek en Yucatán: una nueva interpretación". Desacatos 13 (2003). Web.

Pitarch, Pedro. "Chiapas". El País, 12 de enero 1998. Web.

---. "El testimonio de Rigoberta Menchú". Revista de Libros 37 (2000). Web.

"Presentación de una nueva serie". México Indígena 5 (1977): 13-14. Impreso.

Taibo, Carlos. Anarquistas de ultramar. Anarquismo, indigenismo, descolonización. Madrid: Los Libros de la Catarata, 2018. Impreso.

Taylor, Analisa. "The ends of indigenismo in Mexico". Journal of Latin American Cultural Studies 14:1 (2005): 75-86. Impreso.

Tyras, Georges. Geometrías de la memoria. Conversaciones con Manuel Vázquez Montalbán. Granada: Zoela Ediciones, 2003. Impreso.

Vázquez Montalbán, Manuel. Y Dios entró en La Habana. Madrid: El País / Aguilar, 1998. Impreso.

---. "Rigoberta". El País, 11 enero 1999. Web.

--- Marcos: el señor de los espejos. Madrid: El País/Aguilar, Madrid, 1999. Impreso.

---. Memoria y deseo. Obra poética (1963-1990). Barcelona: DeBolsillo, 2005. Impreso.

Villoro, Luis. Los grandes momentos del indigenismo en México. México DF: El Colegio de México/ El Colegio Nacional/Fondo de Cultura Económica, 1998. Impreso. 